\title{
INFLUÊNCIA DE SEIS PORTA-ENXERTOS SOBRE A PRODUÇÃO DE CLONES SUPERIORES DE SERINGUEIRA ( $\left.{ }^{1}\right)$
}

\author{
ÁTILA BENTO BELETI CARDINAL $\left({ }^{2}\right)$; PAULO DE SOUZA GONÇALVES $\left(3^{*}\right)$; \\ ANTÔNIO LÚCIO MELLO MARTINS $\left({ }^{4}\right)$
}

\begin{abstract}
RESUMO
Na cultura da seringueira [Hevea brasiliensis (Willd. ex Adr. de Juss.) Muell.-Arg.] o método de propagação mais utilizado é a enxertia. No entanto, observa-se que a uniformidade esperada pela propagação vegetativa não é verificada em condições de campo, pois altas variações para as variáveis vigor e produção de borracha são detectadas em seringais comerciais, causados pela influência dos portaenxertos utilizados. Com base nesse impedimento e na importância econômica da cultura para o Estado de São Paulo, este trabalho teve por objetivo principal indicar as melhores combinações de clones com porta-enxertos clonais para plantio no Estado, visando-se à alta produção de borracha. Foram analisados dados de cinco anos de produção de borracha seca de um experimento em parcela subdividida com quatro repetições, desenvolvido em Pindorama (SP). Os tratamentos constaram de seis porta-enxertos (GT 1; IAN 873; PB 235; RRIM 600; RRIM 701 e sementes não-selecionadas - SNS) e seis enxertos (GT 1; IAN 873; PB 235; PR 107; RRIM 600 e RRIM 701), totalizando 36 diferentes combinações, e os métodos de análise constaram de análise de variância individual e comparação de médias. Observou-se efeito pronunciado de porta-enxertos sobre a variável analisada, bem como comportamento diferencial entre as combinações testadas. A partir dos resultados, pôde-se concluir que os porta-enxertos PB 235, GT 1 e IAN 873 foram os que proporcionaram maiores rendimentos, podendo ser recomendados com segurança para as condições do Planalto Paulista; o uso de SNS como porta-enxerto não é recomendado, pois os rendimentos foram muito baixos quando comparado aos demais porta-enxertos testados.
\end{abstract}

Palavras-chave: Hevea, borracha natural, enxertia, propagação vegetativa.

\section{ABSTRACT \\ INFLUENCE OF SIX ROOTSTOCKS ON YIELD OF SUPERIOR RUBBER TREE CLONES}

In the rubber tree cultivation [Hevea brasiliensis (Willd. ex Adr. de Juss.) Muell.-Arg.], the most used propagation method is budding. The expected uniformity by using vegetative propagation is however not verified in fields commercial, because high variation for vigour and yield traits are induced by the rootstocks used. Based on this issue and on the economical importance of the rubber tree in São Paulo State, this study had as main objective the indication of the best combination of clones and rootstocks for planting in the State, aiming at high vigour and productivity. Analysed data were five years of dry rubber yield from an experiment in split-plot design with four replications, conducted at Pindorama (SP). Treatments comprised 36 different combinations, subjected to analysis of variance and mean comparions of six rootsocks and six scions. It was observed strong effects of rootstock over the anylised variables, as well as differential behaviour among the tested combinations. It was concluded that, PB 235, GT 1 and IAN 873 induced the largest yields, and should be recommended to the conditions of Planalto Paulista; the use of unselected seedlings (SNS) as rootstocks is not recommended as it showed very low yields when compared to selected rootstock seedlings.

Key words: Hevea, natural rubber, budding, vegetative propagation.

$\left({ }^{1}\right)$ Recebido para publicação em 3 de abril de 2006 e aceito em 5 de fevereiro de 2007.

$\left({ }^{2}\right)$ Mestrando PG-IAC em Tecnologia da Produção Agrícola. Bolsista FAPESP.

$\left({ }^{3}\right)$ Programa Integrado Embrapa-IAC, Programa Seringueira, Instituto Agronômico (IAC), Caixa Postal 28, $13012-970$ Campinas (SP). E-mail: paulog@iac.sp.gov.br. $\left(^{*}\right)$ Autor correspondente.

( ${ }^{4}$ ) Pólo Regional de Desenvolvimento Tecnológico dos Agronegócios do Centro Norte, Caixa Postal 24, 15830-000 Pindorama (SP). 


\section{INTRODUÇÃO}

A seringueira [Hevea brasiliensis (Willd. ex Adr. de Juss.) Muell.-Arg.], pertencente à família Euphorbiaceae, é a espécie de maior importância econômica dentro do gênero e a única plantada comercialmente (GoNÇALVES et al., 1989).

Segundo IRSG (2006), a produção mundial de borracha seca em 2005 foi de 8,46 milhões de toneladas e, atualmente, os maiores produtores e exportadores de borracha são os países do sudeste asiático, sendo a Tailândia o país com maior produção, (2,90 milhões de toneladas ou $34 \%$ do total mundial), seguida pela Indonésia (1,85 milhões de toneladas, representando $22 \%$ do total), Índia e Malásia. O Brasil, apesar de já ter tido o monopólio da produção de borracha natural no início do século XX, possui atualmente uma produção pouco expressiva, de 100 mil toneladas, enquanto seu consumo chega a 270 mil toneladas.

As condições climáticas adequadas, que minimizam os riscos de insucesso, e também os altos rendimentos proporcionados pela cultura nos últimos anos são os principais fatores que elevaram São Paulo à condição de maior produtor de borracha natural, desde 1995, respondendo por aproximadamente metade da produção total no país. O Planalto Ocidental do Estado engloba $90 \%$ da área plantada, onde se situa a região mais importante de cultivo e que representa quase a metade de toda a área explorada com seringueira no Brasil (GoNÇALVES et al., 2001).

Para implantação de plantios comerciais, a seringueira pode ser multiplicada tanto pela via sexuada como assexuada (vegetativa). Por ser uma planta alógama com alto grau de segregação e visto que linhagens homozigóticas ainda levarão muito tempo para serem obtidas, a enxertia caracteriza-se como o método mais prático e usual para sua multiplicação, visando manter a integridade genotípica dos clones.

O método mais empregado atualmente é o da enxertia por borbulha em porta-enxertos provenientes de sementes. Dessa forma, para plantações comerciais, os clones são escolhidos em razão de sua adaptabilidade ao local e de sua produtividade; já no que se refere aos porta-enxertos, pouca importância lhes é dada quanto à sua procedência ou origem genética desde que tenham diâmetro suficiente para o processo de enxertia (MARTins et al., 2000).

Considerando-se que o método de enxertia asseguraria que o enxerto (porção superior da árvore) de um bloco monoclonal fosse isogênico, observa-se, no entanto, que na maioria dos seringais essa uniformidade esperada pela propagação vegetativa não ocorre. São constatados altos coeficientes de variação para vigor e produção de borracha, causados pela variabilidade devido à própria origem sexuada dos porta-enxertos, uma vez que são multiplicados por sementes e sujeitos à segregação (ocorrendo, portanto, falta de uniformidade nos porta-enxertos). Além desses fatores, a incompatibilidade entre enxertos e porta-enxertos, fatores climáticos, adubação e técnica de enxertia utilizada podem influenciar a relação estabelecida entre os materiais utilizados para propagação da cultura.

Em seringueira, apesar dos estudos dessa ordem serem escassos, os existentes têm mostrado a influência significativa do porta-enxerto no crescimento e na produção do enxerto.

Segundo Ferwerda (1969), a variação de desempenho entre uma planta-mãe e um enxerto derivado dela é devido a dois fatores principais: (a) ao processo de enxertia per se (estresse causado pelo processo de propagação vegetativa); e (b) a resposta à situação de simbiose forçada com um porta-enxerto estranho (incompatibilidade em maior ou menor grau).

Os estudos pioneiros sobre a relação enxerto $v s$. porta-enxerto em seringueira resultaram em informações obtidas a partir de experimentos desenvolvidos na Ásia e na África por BUTTERY (1961), Yahampath (1968), Combe e Gerner (1977) e NG et al. (1982). Porém, a influência recíproca entre enxerto e porta-enxerto de Hevea foi comprovada pela primeira vez por Hoop e Ostendorf em 1932, conforme SANTOS (1982). Ressalta-se, no entanto, que esses experimentos, em sua maioria, foram desenvolvidos em diferentes famílias de porta-enxertos de pésfrancos, produzindo resultados inconstantes e cuja utilização prática era limitada pela inexistência de quantidades suficientes de sementes que pudessem ser amplamente utilizadas pelos produtores da época.

Com base na limitação identificada e na importância da heveicultura para o Estado, os objetivos principais do presente trabalho foram: (a) verificar se existe efeito de diferentes porta-enxertos sobre a produção e o vigor de clones superiores de seringueira, e (b) identificar as melhores combinações de enxerto e porta-enxerto para obtenção máxima de vigor e produtividade.

\section{MATERIAL E MÉTODOS}

O experimento vem sendo desenvolvido desde 1990 e está instalado na antiga Estação Experimental de Pindorama do Instituto Agronômico (IAC), atualmente Pólo Regional de Desenvolvimento 
Tecnológico dos Agronegócios do Centro-Norte da Agência Paulista de Tecnologia dos Agronegócios (APTA), em Pindorama, Estado de São Paulo. Localiza-se a $21^{\circ} 13^{\prime} \mathrm{S}$ de latitude e $48^{\circ} 56^{\prime} \mathrm{W}$ de longitude, a uma altitude de $560 \mathrm{~m}$. O solo é caracterizado como Argissolo Vermelho-amarelo Tb eutrófico abrúptico, textura média, profundo e bem drenado. Segundo Ortolani (1986), o clima predominante na região é tropical continental, ou Aw, segundo a classificação de Köppen, com estação seca definida, amplitude média de $19,3^{\circ} \mathrm{C}$ a $23,8^{\circ} \mathrm{C}$ e precipitação pluvial média de $1.258 \mathrm{~mm}$ ao ano. As deficiências hídricas e os baixos níveis térmicos ocorrem de junho ao início de setembro, com um período favorável ao crescimento da seringueira nos meses de outubro a março.

Seis materiais compreenderam os portaenxertos estudados, a saber: GT 1 (clone primário); IAN 873 (PB $86 \times$ FA 1717); PB 235 (PB 5/51 x PB S.78); RRIM 600 (Tijir 1 x PB 86); RRIM 701 (44/553 $x$ RRIM 501) e sementes não-selecionadas (SNS), todos originários de clones/populações intraespecíficas de Hevea brasiliensis. Já os clones utilizados como enxertos, também em número de seis, foram: GT 1; IAN 873; PB 235; PR 107; RRIM 600 e RRIM 701. Os enxertos (clones) e porta-enxertos foram enxertados proporcionando um total de 36 combinações.

As sementes dos porta-enxertos IAN 873, RRIM 600 e RRIM 701 foram coletadas dentro de parcelas do experimento de avaliação de clones do Programa Seringueira do IAC, estabelecido na Fazenda Água Milagrosa, em Tabapuã, SP. Os clones GT 1 e PB 235 tiveram as sementes coletadas de propriedade do Sr. Luiz Taktene, no município de Marília, SP. Para a coleta das sementes preferiram-se sempre os frutos expostos nas laterais e extremidades dos blocos monoclonais, conforme as recomendações de BouYcHOU (1969). As sementes não-selecionadas foram coletadas de uma população de pés-francos existentes no Pólo Regional de Pindorama.

Colhidos os frutos e separadas as sementes, procedeu-se à semeadura em canteiros de germinação. Na fase de mudas tipo "palito", as mudas foram transplantadas para sacos de polietileno. Após dez meses, essas mudas foram transferidas para o local definitivo.

A enxertia foi realizada 12 meses após a instalação dos porta-enxertos clonais no campo, usando-se borbulhas maduras dos clones. Cada portaenxerto recebeu borbulhas dos clones GT 1, IAN 873, PB 235, PR 107, RRIM 600 e RRIM 701, provenientes do jardim clonal do Pólo Regional já referido, seguindo um esquema do tipo dialélico que contemplou todas as combinações possíveis.
O delineamento experimental utilizado foi o de blocos ao acaso, no esquema em faixas, constituído de seis tratamentos (porta-enxertos) e seis subtratamentos (enxertos), com quatro repetições.

As parcelas constituíram-se de 120 árvores; cada subparcela com 20 plantas, sendo seis úteis (as demais formam bordadura simples, ou seja, do próprio tratamento da parcela), instaladas no espaçamento 7,0 $\mathrm{m}$ entre linhas e 3,0 $\mathrm{m}$ entre plantas na linha. A área total do experimento é de 6,0 hectares.

Durante a realização do experimento, empregaram-se todas as práticas culturais, convencionais ao cultivo da seringueira, como descrito por CARDOSO (1982) e GonçALVES et al. (2001).

As árvores tiveram o painel de sangria aberto quando $50 \%$ ou mais das plantas atingiram perímetro do caule igual ou superior a $45 \mathrm{~cm}$ a uma altura de $1,30 \mathrm{~m}$ do calo de enxertia. $\mathrm{O}$ sistema de sangria obedeceu $1 / 2 \mathrm{~S} \mathrm{~d} / 4$ dd/7.11m/y ET 2,5\% Ga 8/y, ou seja, sangria em meia espiral (1/2 $S)$, realizada em intervalos de quatro dias (d/4) com atividade de sangria em cinco dias na semana $(5 \mathrm{~d} / 7)$, durante 11 meses no ano $(11 \mathrm{~m} / \mathrm{y})$; a estimulação com $2,5 \%$ de etephon (ET 2,5\%) na canaleta sem cernambi $(\mathrm{Ga})$ ocorreu oito vezes por ano $(8 / y)$.

O registro da produção por combinação (enxerto/porta-enxerto) foi efetuado pelo látex coagulado nas tigelas, coletado ao acaso, duas vezes ao mês, seco em condições normais de sombra e ventilação, preso a cada árvore na forma de coágulo, ao longo do período de avaliação. A massa total anual de borracha por árvore foi dividida pelo número de coágulos, sendo o resultado expresso em gramas árvore $^{-1}$ sangria $^{-1}$.

De posse dos dados disponíveis, realizou-se análise de variância, considerando-se médias de parcelas, de acordo com o seguinte modelo:

$Y_{i j k}$, em que:

$Y_{i j k}=$ observação da combinação do portaenxerto $P$ com o enxerto $S$ no bloco $B$;

$\mu=$ média geral;

$B_{j}=$ efeito do $j$-ésimo bloco;

$P_{i}=$ efeito do $i$-ésimo porta-enxerto;

$e_{i j}=$ erro a;

$S_{k}=$ efeito do $k$-ésimo enxerto;

$e_{k j}=$ erro b;

$P S_{i k}=$ efeito da interação do $i$-ésimo portaenxerto com o $k$-ésimo enxerto; e,

$$
e_{i j k}=\text { erro c. }
$$


O teste de comparação de médias utilizado foi DMS de Fischer, a 5\% de probabilidade de erro.

Os dados foram analisados, utilizando-se os procedimentos do programa estatístico computacional "Genes" versão Windows (CRUZ, 2001).

\section{RESULTADOS E DISCUSSÃO}

Na tabela 1 estão contidos os resultados da análise de variância referentes a cinco anos de avaliação, à média de cinco anos e ao total de produção nos cinco anos avaliados. Foi detectado efeito de portaenxerto sobre essa variável em todos os cinco anos de avaliação (significativo no terceiro e quarto anos; altamente significativo nos demais anos avaliados).

Esse cenário permite concluir que o portaenxerto tem capacidade de interferir no resultado produtivo das combinações de enxerto e porta-enxerto de seringueiras testadas, concordando os resultados de Combe e Gerner (1977). Esses autores observaram efeito significativo de porta-enxerto sobre a variável produção, testando três clones enxertados sobre quatro famílias de porta-enxertos obtidos de sementes ilegítimas; mais tarde, NG et al. (1982) também verificaram efeito significativo de porta-enxerto em um experimento de seis porta-enxertos $\mathrm{x}$ seis enxertos em Mallaca, Malásia. Na mesma configuração de resultados, NG (1983) também reportou efeito significativo de porta-enxerto, testando cinco portaenxertos $\mathrm{x}$ cinco enxertos em um ensaio desenvolvido em Negeri Sembillan, Malásia.

Como não houve interação significativa entre os fatores principais, segundo a análise de variância previamente discutida, o desempenho de ambos os grupos de materiais pôde ser analisado de forma isolada. Dessa forma, na tabela 2, os porta-enxertos estão representados como efeitos isolados sobre a variável.

No primeiro ano de avaliação, os porta-enxertos PB 235 e RRIM 600 foram os que proporcionaram as maiores produções, seguidos de IAN 873 e GT 1. Esses quatro porta-enxertos formaram um grupo estatisticamente homogêneo e superior aos dois outros materiais (RRIM 701 de comportamento estatisticamente igual ao de IAN 873 e GT 1; o porta-enxerto SNS diferiu de todos os demais, com baixo desempenho).

No segundo ano, observou-se desempenho superior dos porta-enxertos PB 235 e IAN 873, enquanto o SNS proporcionou baixas produções aos clones sobre ele enxertados, diferindo estatisticamente de todos os outros cinco porta-enxertos.

Para o terceiro ano de avaliação da produção de borracha seca, PB 235 e GT 1 foram os melhores porta-enxertos, embora com desempenhos não diferentes de IAN 873 e RRIM 600 pelo teste DMS de Fischer a $5 \%$ de probabilidade de erro.

Em relação ao quarto ano de avaliação da variável produção, foi possível separar os seis portaenxertos em três grupos estatisticamente homogêneos. O porta-enxerto PB 235 foi o de melhor desempenho, com média de produção dos clones sobre ele enxertados de cerca de $20 \%$ maior do que a média do segundo grupo (RRIM 600, GT 1, IAN 873 e RRIM 701), enquanto SNS repetiu o desempenho dos períodos anteriores, com uma média de produção dos clones enxertados sobre ele muito inferior aos demais porta-enxertos.

No quinto ano, PB 235 novamente foi o portaenxerto com melhor desempenho; no entanto, para esse período de avaliação, não foi possível detectar diferença estatística significativa desse material em relação aos outros dois (GT 1 e IAN 873, sendo esses últimos estatisticamente semelhantes ao RRIM 600 e ao RRIM 701 pelo teste de comparação de médias). O pior porta-enxerto foi o SNS, que proporcionou produção média dos clones sobre ele enxertados de 33,05 g árvore $^{-1}$ sangria $^{-1}$, representando um desempenho $30 \%$ inferior à média geral do experimento (45,32 g árvore ${ }^{1}$ sangria $^{-1}$ ) no mesmo período.

Na média de cinco anos e na produção acumulada de cinco anos, o desempenho dos portaenxerto PB 235 foi superior em relação à quatro outros materiais, com desempenho similar apenas ao de IAN 873. Observaram-se em quatro porta-enxertos comportamento estatisticamente não-diferente segundo o teste de médias, a saber: IAN 873, RRIM 600, GT 1 e RRIM 701. O pior porta-enxerto nessas duas condições de análise, tal como ocorreu nas cinco avaliações anuais, foi o SNS, claramente separado dos demais materiais pelo teste de comparação de médias.

$\mathrm{Na}$ tabela 3 estão contidos os resultados de produção analisando-se as 36 diferentes combinações (todos os seis clones sobre cada um dos seis portaenxertos), refletindo o comportamento individual das combinações em relação às testemunhas (cada enxerto x SNS).

Para o clone GT 1, levando-se em conta o total de cinco anos de avaliação da produção de borracha seca, o porta-enxerto que induziu maior produção foi PB 235 (41\% superior ao desempenho de quando enxertado sobre SNS), tal como ocorreu no primeiro, quarto e quinto anos de avaliação com $44 \%, 33 \%$ e $50 \%$ de aumento em relação à testemunha. IAN 873 destacou-se como porta-enxerto para o clone GT 1 apenas no segundo ano, com boa eficiência também no total de cinco anos, proporcionando um aumento de $37 \%$ em comparação ao SNS. 

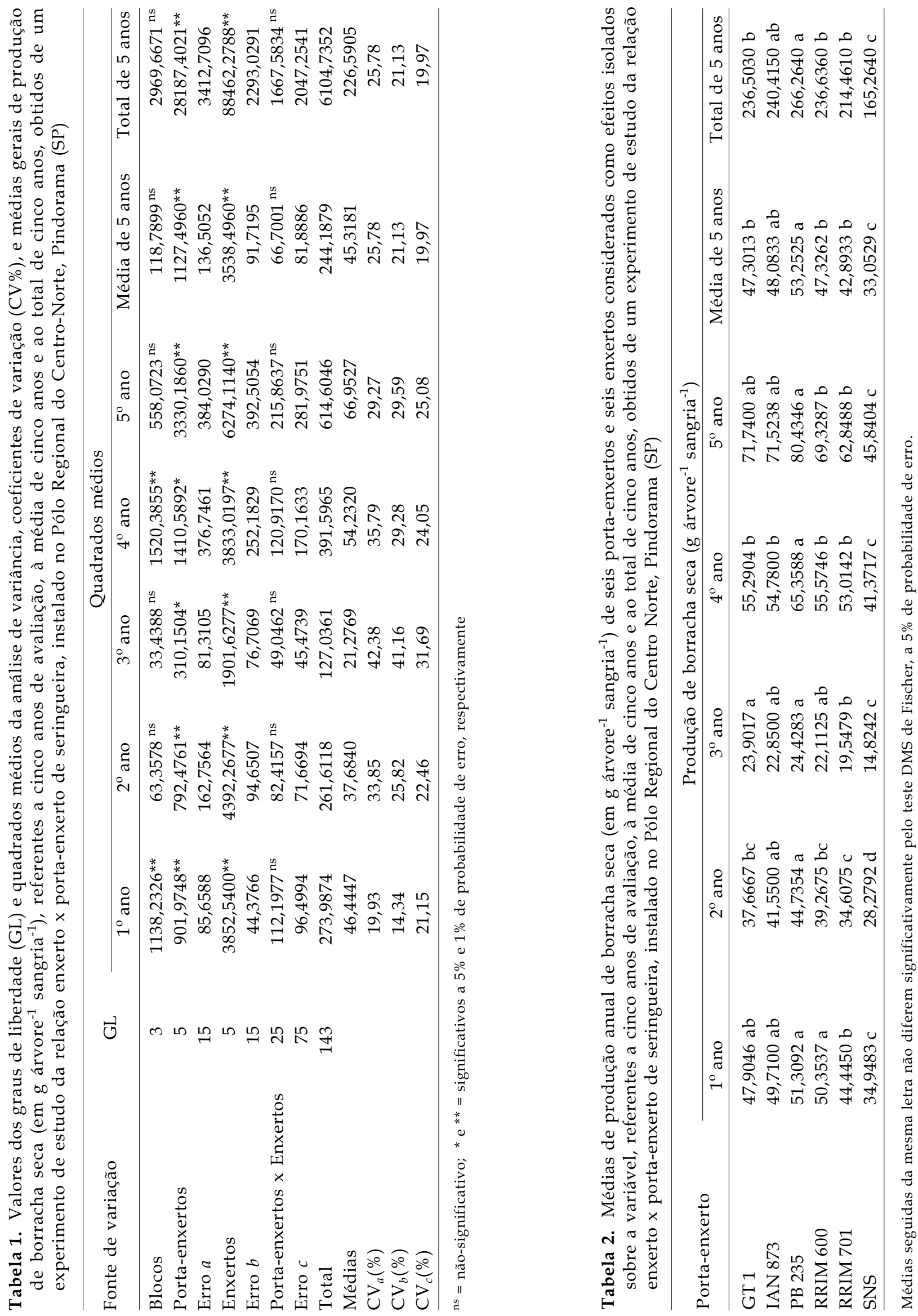


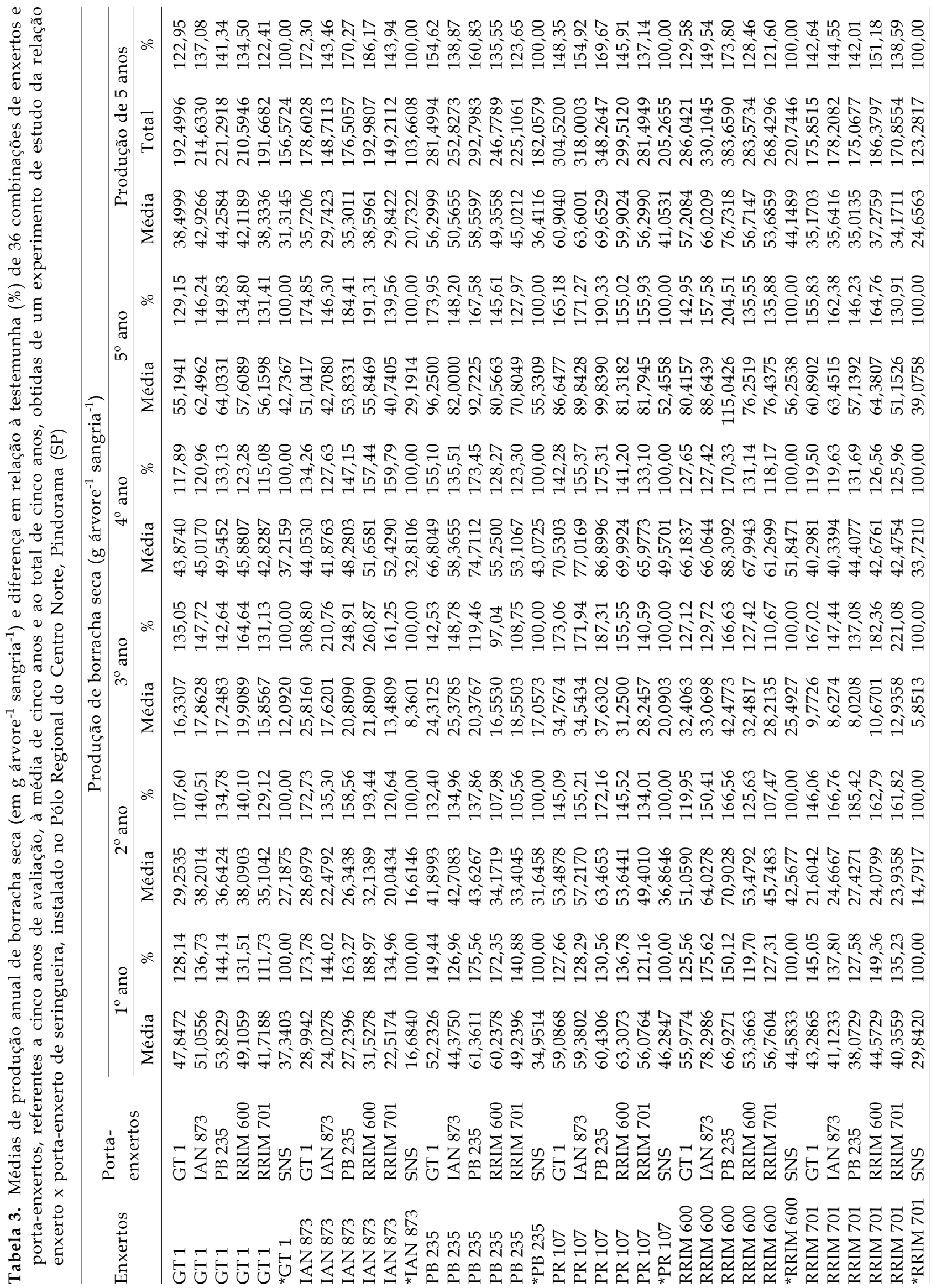

Bragantia, Campinas, v.66, n.2, p.277-284, 2007 
Usando a combinação GT $1 \times$ SNS como testemunha em ensaio com 18 clones na mesma localidade em que foi conduzido o presente trabalho, GONÇALVES et al. (2002) observaram produção média de 31,31 g árvore $^{-1}$ sangria $^{-1}$, nos dois primeiros anos de produção, muito próxima à média dos dois primeiros anos encontrada nesse estudo $(32,26 \mathrm{~g}$ árvore $^{-1}$ sangria $^{-1}$ ) para a mesma combinação de enxerto $x$ porta-enxerto.

A produção média do clone IAN 873, quando enxertado sobre porta enxerto SNS, nas condições testadas, foi de $20,73 \mathrm{~g}$ árvore ${ }^{-1}$ sangria $^{-1}$, um pouco inferior ao resultado verificado por GoNÇALVES et al. (2000), que testaram esse clone como testemunha em um experimento com 20 clones (todos enxertados em porta-enxertos obtidos de polinização aberta de uma população de pés-francos - SNS) em Pariqüera-Açú, no Vale do Ribeira, Estado de São Paulo e determinaram uma produção média em três anos de avaliação de 25,20 g árvore ${ }^{-1}$ sangria $^{-1}$.

Apesar das baixas médias de produção do clone IAN 873, em todos os períodos avaliados, como já discutido, o melhor porta-enxerto para esse material, nas condições de teste, foi o RRIM 600, que proporcionou produções $86 \%$ maiores do que com o uso de SNS.

No que se refere ao enxerto PB 235, o melhor porta-enxerto é aquele obtido de sementes do próprio clone; GT 1 também pode ser considerado uma boa escolha quando observado o comportamento produtivo ao longo de cinco anos de avaliação, de modo que esses dois porta-enxertos obtiveram produções cerca de $60 \%$ maiores quando comparadas ao porta-enxerto testemunha (SNS).

Com relação ao enxerto PR 107, novamente é notada a superioridade do porta-enxerto PB 235, capaz de induzir produções até $70 \%$ maiores a esse clone do que quando utilizado o porta-enxerto de sementes não-selecionadas.

Quando se analisa o desempenho de portaenxertos para o clone RRIM 600, nota-se superioridade de IAN 873 para o primeiro ano, embora nos períodos subseqüentes de avaliação, o porta-enxerto PB 235 tenha superado todos os outros cinco materiais testados. Especificamente, no quinto ano de produção de borracha seca, esse material foi capaz de sustentar uma produção equivalente ao dobro daquela obtida com o porta-enxerto testemunha (induzindo uma produção 104\% maior do que a base de comparação), e na média de cinco anos, proporcionou rendimentos $74 \%$ maiores do que SNS.

No primeiro ano, com o clone RRIM 600 enxertado sobre SNS, obteve-se uma produção de
44,58 $\mathrm{g}$ árvore $^{-1}$ sangria $^{-1}$, enquanto Pereira et al. (1999) verificou, em Goiânia, Estado de Goiás, valores bem menores, de 21,20 g árvore ${ }^{-1}$ sangria $^{-1}$. Essa baixa produção observada pelos autores pode ser devida às condições edafoclimáticas menos adequadas quando comparadas à condição em que este experimento foi desenvolvido, embora o porta-enxerto utilizado tenha similaridade com o testado neste trabalho.

GonçALves et al. (1999) constataram uma produção no primeiro ano de sangria, para esse mesmo clone, de 18,26 g árvore ${ }^{-1}$ sangria $^{-1}$, nas condições de Votuporanga (SP), utilizando porta-enxertos SNS com a mesma origem do utilizado neste experimento. No município de Jaú, Estado de São Paulo, GonçALVES et al. (1994) verificaram uma produção de RRIM 600 x SNS, no primeiro ano, de $13,28 \mathrm{~g}_{\text {árvore }}{ }^{-1}$ sangria $^{-1}$ (na média de quatro anos, foi obtido um valor de 18,13 g árvore ${ }^{-1}$ sangria $^{-1}$ ). Já em Pindorama, no mesmo Estado, foram relatadas por GoNçALVEs et al. (2002) produções de RRIM 600 x SNS de aproximadamente 26,39 e 40,17 g árvore $^{-1}$ sangria $^{-1}$; nos dois primeiros anos de avaliação, respectivamente (com média de 33,28 g árvore $^{-1}$ sangria $\left.^{-1}\right)$. Nos três casos, os valores foram inferiores aos obtidos neste estudo $(44,15 \mathrm{~g}$ árvore $^{-1}$ sangria $^{-1}$ em cinco anos de avaliação).

Para o clone RRIM 701, o porta-enxerto capaz de induzir a maior produção foi o RRIM 600, embora em outros quatro porta-enxertos observou-se comportamento muito semelhante, com ganhos de, no mínimo, 39\% em relação ao total de cinco anos quando comparados ao porta-enxerto SNS.

Ressalta-se que os três porta-enxertos com maior desempenho (PB 235, GT 1 e IAN 873) são oriundos de sementes de clones intra-específicos de $H$. brasiliensis, favorecendo a inexistência de incompatibilidade que poderia ocorrer caso fossem utilizados porta-enxertos com origem de cruzamentos com outras espécies de Hevea. Além disso, sementes de GT 1, normalmente, são mais vigorosas, devido ao fato de esse clone ser macho-estéril, levando à maior uniformidade em relação ao SNS (material sem controle de polinização, com maior variabilidade genética).

\section{CONCLUSÕES}

1. Os resultados deste trabalho permitem concluir que os porta-enxertos testados têm efeito significativo sobre produção dos clones sobre eles enxertados.

2. Os porta-enxertos PB 235, GT 1 e IAN 873 proporcionam maiores rendimentos, podendo ser recomendados com segurança para as condições da heveicultura no Planalto Paulista. 
3. O uso de porta-enxertos obtidos de sementes não-selecionadas (SNS) é desaconselhado, por proporcionar produções muito inferiores aos demais materiais.

\section{AGRADECIMENTOS}

Os autores agradecem à Fundação de Amparo à Pesquisa do Estado de São Paulo (FAPESP) e ao Conselho Nacional de Pesquisa (CNPq) pelo apoio financeiro, bem como às equipes do Programa Seringueira do IAC e do Pólo Regional de Pindorama pelo suporte técnico.

\section{RREFERÊNCIAS}

BOUYCHOU, J.G. La bilogie de l'hévéa. Revue General des Cautchoucs Plastiques, Paris, v. 40, p.933-1001, 1969.

BUTTERY, B.R. Investigations into relationship between stock and scion in budded trees of Hevea brasiliensis. Journal of the Rubber Research Institute of Malaysia, Kuala Lumpur, v.17, p.46-76, 1961.

CARDOSO, M. Instruções para a cultura da seringueira. 3.Ed. Campinas: IAC, 1989. 50p. (Boletim 196)

COMBE, J.C.; GERNER, P. Effect of the stock family on the growth and production of grafted Heveas. Journal of the Rubber Research Institute of Malaysia, Kuala Lumpur, v.54, p.83-92, 1977.

CRUZ, C.D. Programa Genes: versão Windows, Aplicativo computacional em genética e estatística, Viçosa: UFV, 641p., 2001.

FERWERDA, F.P. Rubber. In: FERWERDA, F.P.; WIT, F. Outlines of perennial crop breeding in the tropics. Wageningen: H. Veenan \& Zonenn, 1969. 236p.,

GONÇALVES, P.S., BATAGLIA, O.C.; ORTOLANI, A.A;.FONSECA, F.S. Manual de Heveicultura para o Estado de São Paulo, Campinas: Instituto Agronômico (IAC), 2001. 78p. (Série Tecnologia APTA, 189)

GONÇALVES, P S.; BORTOLETTO, N.; ORTOLANI, A. A.; BELLETTI, G. O.;SANTOS, W. R. Desempenho de novos cones de seringueira: III. Seleções promissoras para a região de Votuporanga, Estado de São Paulo. Pesquisa Agropecuária Brasileira, Brasília, v.34, n.6, p.971-980, 1999.

GONÇALVES, P.S.; CARDOSO, M.; BOAVENTURA, M.A.M.; MARTINS, A.L.M.; LAVORENTI, C. Biologia, citogenética e ploidia de espécies do gênero Hevea. O Agronômico, Campinas, v.41, n.1, p.40-64, 1989.

GONÇALVES, P.S.; CARDOSO, M.; CAMPANA, M.; FURTADO, E.L.; TANZINI , M. R. Desempenho de novos cones de seringueira da série IAC: II. Seleções promissoras para a região do Planalto do Estado de São Paulo. Pesquisa Agropecuária Brasileira, Brasília v.29, n.8, p.1215-1224, 1994.

GONÇALVES, P.S.; MARTINS, A. L. M. Combining ability effects of clonal rootstocks and scions in rubber trees (Hevea). Crop Breeding and Applied Biotechnology, Viçosa, v.2, n.3, p.445-452, 2002

GONÇALVES, P.S.;SAES, L.A.; FURTADO, E.L.;SAMBUGARO, R.; SAKAI, M. Clones promissores de seringueira para o Vale do Ribeira, São Paulo. Pesquisa Agropecuária Brasileira, Brasília v.35, n.12, p.2243-2253, 2000.

INTERNATIONAL RUBBER STUDY GROUP - IRSG.. Rubber production statistics, v.5, n.9-10, 2006.

MARTINS, A.L.M.; RAMOS, N.P.; GONÇALVES, P.S.; VAL, K.S. Influência de porta-enxertos no crescimento de clones de seringueira no Estado de São Paulo. Pesquisa Agropecuária Brasileira, v.35, n.9, p.1743-1750, 2000.

NG, A. P. Performance of rootstocks. Planters' Bulletin, n.175, p.81-87, 1983.

NG, A.P.; HO, C.Y.; SULTAN, M. O.; OOI, C.B.; LEW, H.L.; YOON, P.K. Influence of six rootstocks on growth and yield of six scion clones of Hevea brasiliensis. In: RRIM Planters's CONFERENCE, 1981. Proceedings... London: RRIM, 1982, p.134151, 1982.

ORTOLANI, A. A. Agroclimatologia e o cultivo da seringueira. In: Simpósio sobre a cultura da seringueira no Estado de São Paulo, 1986, Piracicaba. Anais... Campinas: Fundação Cargill, p.11-32, 1986.

PEREIRA, A.; VENTURIN, N.; PEREIRA, E.B.C.; FIALHO, J.F.; JUNQUEIRA, N.T.V.; GONÇALVES, P.S. Avaliação preliminar do desempenho de clones de seringueira (Hevea spp.) na região de Goiânia. Cerne, Lavras , v.5, n.1, p.24-35, 1999.

SANTOS, P.M. Efeito da interação enxerto x porta-enxerto em seringueira (Hevea spp.). 1982, 68p.. Dissertação (Mestrado) Escola Superior de Agricultura "Luiz de Queiroz" Universidade de São Paulo, , Piracicaba, 1982.

YAHAMPATH, C. Growth rate of PB 86 on different Hevea rootstocks. Rubber Research Institute of Ceylon Quarterly Journal: Agalawatta, v.74, p.27-28, 1968 